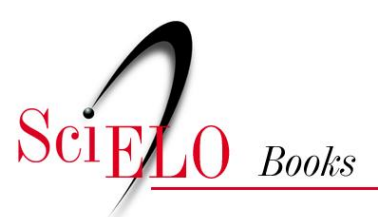

\title{
Ordem Gadiformes
}

\author{
Ana Cristina Teixeira Bonecker \\ Claudia Akemi Pereira Namiki \\ Márcia Salustiano de Castro \\ Paula Nepomuceno Campos
}

\section{SciELO Books / SciELO Livros / SciELO Libros}

BONECKER, ACT., et al. Ordem Gadiformes. In Catalogo dos estágios iniciais de desenvolvimento dos peixes da bacia de Campos [online]. Curitiba: Sociedade Brasileira de Zoologia, 2014, pp. 131139. Zoologia: guias e manuais de identificação series. ISBN 978-85-98203-10-2. Available from

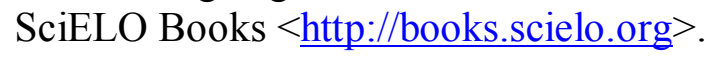

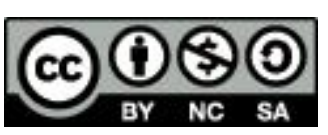

All the contents of this chapter, except where otherwise noted, is licensed under a Creative Commons Attribution-Non Commercial-ShareAlike 3.0 Unported.

Todo o conteúdo deste capítulo, exceto quando houver ressalva, é publicado sob a licença Creative Commons Atribuição Uso Não Comercial - Partilha nos Mesmos Termos 3.0 Não adaptada.

Todo el contenido de este capítulo, excepto donde se indique lo contrario, está bajo licencia de la licencia Creative Commons Reconocimento-NoComercial-CompartirIgual 3.0 Unported. 


\section{ORDEM GADIFORMES}

A ordem Gadiformes é formada por nove famílias com 555 espécies. As nadadeiras pélvicas, quando presentes, estão inseridas abaixo ou a frente das peitorais, com mais de 11 raios. Não possuem espinhos verdadeiros nas nadadeiras. As nadadeiras dorsal e anal são longas na maioria das espécies. As larvas costumam ser muito pigmentadas e a nadadeira caudal pode ser presente ou ausente. Muitos peixes comercialmente importantes pertencem a esta ordem e representam mais de um quarto da pesca mundial.

Nesse estudo a ordem Gadiformes é representada pelas famílias Bregmacerotidae, Macrouridae e Phycidae. 


\section{Família Bregmacerotidae}

Os peixes da família Bregmacerotidae são pequenos, possuem hábito pelágico e apresentam uma distribuição circumglobal tanto em águas costeiras quanto em regiões oceânicas. Os adultos de algumas espécies realizam migração vertical e distribuem-se desde a superfície até aproximadamente $4.000 \mathrm{~m}$ de profundidade, sendo mais comuns até $300 \mathrm{~m}$. As larvas podem ser coletadas até $600 \mathrm{~m}$ de profundidade e as espécies com distribuição mais costeira tendem a permanecer mais próximas à superfície. Esta família é composta por um único gênero (Bregmaceros) com no mínimo 15 espécies.

No Brasil já foram identificadas três espécies nas fases de larva e adulto: Bregmaceros atlanticus Goode \& Bean, 1886; Bregmaceros cantori (Milliken \& Houde, 1984) e Bregmaceros nov sp. Na área de estudo são contempladas as espécies Bregmaceros atlanticus e Bregmaceros nov sp. 


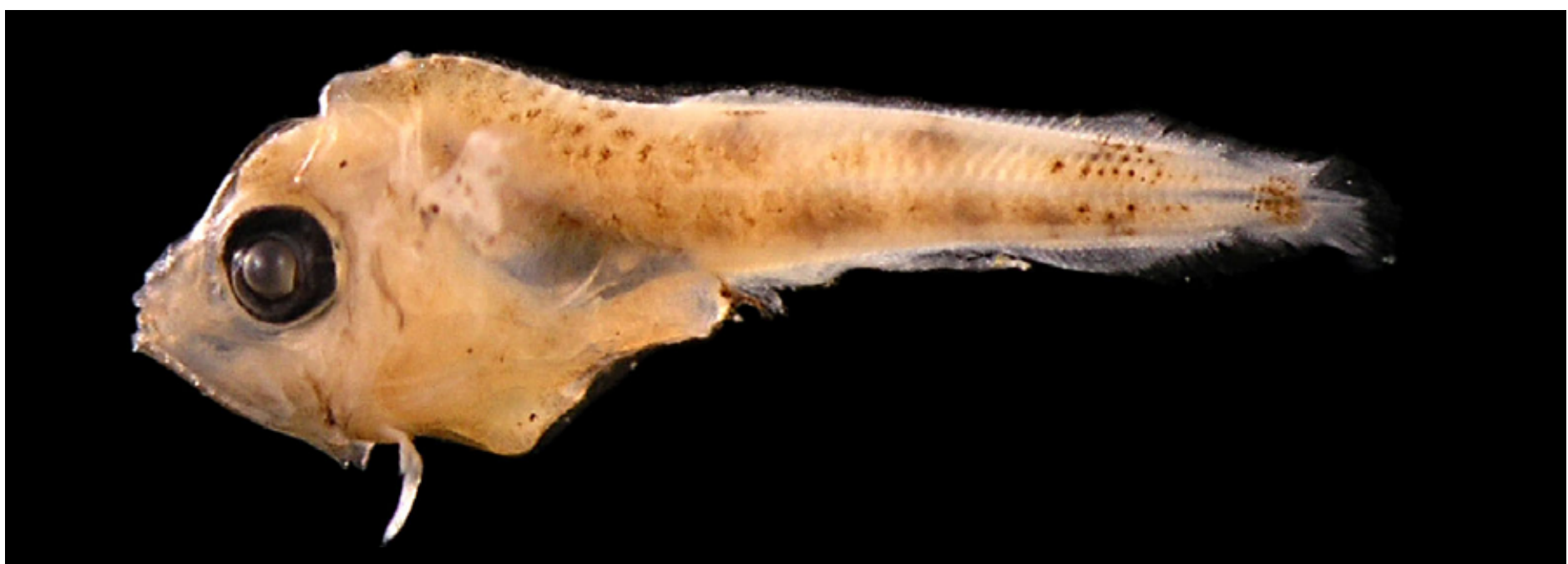

Figura 80- A: Bregmaceros atlanticus. DZUFRJ 13147; Pré-flexão; CP 4,2 mm.

\section{Bregmaceros atlanticus Goode \& Bean, 1866}

Possui intestino curto e corpo alongado (50-55 miômeros). Em larvas em pré-flexão (2,5-4,2 mm) aparecem pequenos melanóforos espalhados pela cabeça. Pigmentos na base da nadadeira, sobre a massa visceral e no lado ventral do intestino. Apresentam de dois a três melanóforos dorsais e de três a quatro melanóforos ventrais. Nadadeira anal e pedúnculo caudal começam a apresentar pigmentos. A partir de $4 \mathrm{~mm}$ os melanóforos espalhados pelo corpo se tornam mais numerosos. No estágio de flexão em diante (larvas maiores que 5,0 $\mathrm{mm}$ ) aparece um raio prolongado localizado na região superior da cabeça, denominado raio occipital.

Tamanho: pré-flexão 2,0-4,2 mm; flexão 4,4-10,0 mm; pós-flexão 12,0-17,0 mm.

Habitat: espécie marinha, epi-mesopelágica, ocorre em águas oceânicas e costeiras.

\section{Georreferencimento}

\begin{tabular}{|c|c|c|c|c|c|c|c|c|}
\hline DZUFRJ & Latitude (S) & Longitude (W) & Data & $\begin{array}{l}\text { Tipo de } \\
\text { arrasto }\end{array}$ & $\begin{array}{c}\text { Profundidade } \\
\text { de coleta }\end{array}$ & Rede & $\begin{array}{l}\text { Malha } \\
(\mu \mathrm{m})\end{array}$ & $\begin{array}{l}N^{\circ} \text {. de } \\
\text { inds. }\end{array}$ \\
\hline 1174 & 2 & 9 & $10 / 0$ & oblíquo & $1.000 \mathrm{~m}$ & cilíndric & 500 & 2 \\
\hline 1189 & $22^{\circ} 07^{\prime} 29,0^{\prime \prime}$ & $039^{\circ} 06^{\prime} 23,5^{\prime \prime}$ & $10 / 05 / 2002$ & oblíquo & $1.000 \mathrm{~m}$ & cilíndrico-cônica & 500 & 4 \\
\hline 1252 & $22^{\circ} 08^{\prime} 17,5^{\prime \prime}$ & $39^{\circ} 46^{\prime} 28,5^{\prime \prime}$ & $11 / 05 / 2002$ & oblíquo & 1.0 & cilíndric & 500 & 3 \\
\hline 6217 & $22^{\circ} 33^{\prime} 47,7^{\prime \prime}$ & $040^{\circ} 12^{\prime} 20,5^{\prime \prime}$ & $17 / 05 / 2002$ & oblíquo & $50 \mathrm{~m}$ & & 500 & 6 \\
\hline 533 & $22^{\circ} 34^{\prime} 05,0^{\prime \prime}$ & $040^{\circ} 19^{\prime} 40,0^{\prime \prime}$ & $17 / 05 / 2002$ & oblíquo & $600 \mathrm{~m}$ & cilíndrico-cônica & 500 & 6 \\
\hline 599 & $22^{\circ} 38^{\prime} 29,0^{\prime \prime}$ & $040^{\circ} 17^{\prime} 40,0^{\prime \prime}$ & $18 / 05 / 2002$ & oblíquo & $800 \mathrm{~m}$ & cilíndrico-cônica & 500 & 11 \\
\hline
\end{tabular}




\begin{tabular}{|c|c|c|c|c|c|c|c|c|}
\hline DZUFRJ & Latitude (S) & Longitude (W) & Data & $\begin{array}{l}\text { Tipo de } \\
\text { arrasto }\end{array}$ & $\begin{array}{c}\text { Profundidade } \\
\text { de coleta }\end{array}$ & Rede & $\begin{array}{c}\text { Malha } \\
\text { ( } \mu \mathrm{m})\end{array}$ & $\begin{array}{l}\text { No. de } \\
\text { inds. }\end{array}$ \\
\hline 656 & $22^{\circ} 41^{\prime} 54,7^{\prime \prime}$ & $040^{\circ} 14^{\prime} 04,5^{\prime \prime}$ & $16 / 05 / 2002$ & oblíquo & $1.000 \mathrm{~m}$ & cilíndrico-cônica & 500 & 7 \\
\hline 708 & $22^{\circ} 37^{\prime} 35,5^{\prime \prime}$ & $040^{\circ} 09^{\prime} 32,8^{\prime \prime}$ & $16 / 05 / 2002$ & oblíquo & $1.000 \mathrm{~m}$ & cilíndrico-cônica & 500 & 2 \\
\hline 7476 & $21^{\circ} 57^{\prime} 10,5^{\prime \prime}$ & $039^{\circ} 43^{\prime} 33,3^{\prime \prime}$ & 09/10/2001 & oblíquo & $1.000 \mathrm{~m}$ & cilíndrico-cônica & 500 & 1 \\
\hline 7473 & $21^{\circ} 57^{\prime} 10,5^{\prime \prime}$ & $039^{\circ} 43^{\prime} 33,3^{\prime \prime}$ & 09/10/2001 & oblíquo & $1.000 \mathrm{~m}$ & cilíndrico-cônica & 500 & 5 \\
\hline 7475 & $21^{\circ} 57^{\prime} 10,5^{\prime \prime}$ & $039^{\circ} 43^{\prime} 33,3^{\prime \prime}$ & 09/10/2001 & oblíquo & $1.000 \mathrm{~m}$ & cilíndrico-cônica & 500 & 4 \\
\hline 7479 & $21^{\circ} 54^{\prime} 36,5^{\prime \prime}$ & $039^{\circ} 45^{\prime} 20,0^{\prime \prime}$ & 09/10/2001 & oblíquo & $1.000 \mathrm{~m}$ & cilíndrico-cônica & 500 & 1 \\
\hline 7470 & $21^{\circ} 54^{\prime} 36,5^{\prime \prime}$ & $039^{\circ} 45^{\prime} 20,0^{\prime \prime}$ & $10 / 10 / 2001$ & oblíquo & $1.000 \mathrm{~m}$ & cilíndrico-cônica & 500 & 3 \\
\hline 7471 & $21^{\circ} 54^{\prime} 36,5^{\prime \prime}$ & $039^{\circ} 45^{\prime} 20,0^{\prime \prime}$ & $10 / 10 / 2001$ & oblíquo & $1.000 \mathrm{~m}$ & cilíndrico-cônica & 500 & 1 \\
\hline 7478 & $21^{\circ} 53^{\prime} 10,4^{\prime \prime}$ & $039^{\circ} 45^{\prime} 49,9^{\prime \prime}$ & $10 / 10 / 2001$ & oblíquo & $1.000 \mathrm{~m}$ & cilíndrico-cônica & 500 & 4 \\
\hline 7472 & $21^{\circ} 53^{\prime} 10,4^{\prime \prime}$ & $039^{\circ} 45^{\prime} 49,9^{\prime \prime}$ & $10 / 10 / 2001$ & oblíquo & $1.000 \mathrm{~m}$ & cilíndrico-cônica & 500 & 3 \\
\hline 7474 & $21^{\circ} 58^{\prime} 31,0^{\prime \prime}$ & $039^{\circ} 50^{\prime} 29,7^{\prime \prime}$ & $10 / 10 / 2001$ & oblíquo & $1.000 \mathrm{~m}$ & cilíndrico-cônica & 500 & 4 \\
\hline 7477 & $21^{\circ} 58 ' 31,0^{\prime \prime}$ & $039^{\circ} 50^{\prime} 29,7^{\prime \prime}$ & $10 / 10 / 2001$ & oblíquo & $1.000 \mathrm{~m}$ & cilíndrico-cônica & 500 & 3 \\
\hline 5445 & $22^{\circ} 32^{\prime} 50,0^{\prime \prime}$ & $040^{\circ} 04^{\prime} 09,9^{\prime \prime}$ & $06 / 11 / 2001$ & oblíquo & $1.000 \mathrm{~m}$ & cilíndrico-cônica & 500 & 1 \\
\hline 5444 & $22^{\circ} 32^{\prime} 50,0^{\prime \prime}$ & $040^{\circ} 04^{\prime} 09,9^{\prime \prime}$ & $06 / 11 / 2001$ & oblíquo & $1.000 \mathrm{~m}$ & cilíndrico-cônica & 500 & 1 \\
\hline 5443 & $22^{\circ} 32^{\prime} 49,0^{\prime \prime}$ & $040^{\circ} 04^{\prime} 20,9^{\prime \prime}$ & $07 / 11 / 2001$ & oblíquo & $1.000 \mathrm{~m}$ & cilíndrico-cônica & 500 & 1 \\
\hline 22203 & $22^{\circ} 31^{\prime} 58,9^{\prime \prime}$ & $040^{\circ} 02^{\prime} 53,4^{\prime \prime}$ & $07 / 11 / 2001$ & oblíquo & $1.000 \mathrm{~m}$ & cilíndrico-cônica & 500 & 1 \\
\hline 5441 & $22^{\circ} 31^{\prime} 40,9^{\prime \prime}$ & $040^{\circ} 02^{\prime} 39,6^{\prime \prime}$ & $07 / 11 / 2001$ & oblíquo & $1.000 \mathrm{~m}$ & cilíndrico-cônica & 500 & 1 \\
\hline 5442 & $22^{\circ} 31^{\prime} 40,9^{\prime \prime}$ & $040^{\circ} 02^{\prime} 39,6^{\prime \prime}$ & $07 / 11 / 2001$ & oblíquo & $1.000 \mathrm{~m}$ & cilíndrico-cônica & 500 & 1 \\
\hline 22200 & $22^{\circ} 07^{\prime} 58,8^{\prime \prime}$ & $039^{\circ} 49^{\prime} 08,9^{\prime \prime}$ & $02 / 12 / 2002$ & vertical & $200-1.100 m$ & Cilíndrico-cônica & 200 & 1 \\
\hline 22790 & $22^{\circ} 28,52^{\prime}$ & $039^{\circ} 55,47^{\prime}$ & $16 / 06 / 2003$ & vertical & $0-70 m$ & cilíndrico-cônica & 500 & 1 \\
\hline 22202 & $21^{\circ} 57,51^{\prime}$ & $039^{\circ} 49,57^{\prime}$ & $19 / 06 / 2003$ & vertical & $0-95 m$ & cilíndrico-cônica & 500 & 1 \\
\hline 22791 & $21^{\circ} 57,51^{\prime}$ & $039^{\circ} 49,57^{\prime}$ & $19 / 06 / 2003$ & vertical & $100-550 m$ & cilíndrico-cônica & 500 & 1 \\
\hline
\end{tabular}

Referências: Houde, 1981; Houde, 1984; Matsuura et al., 1993; Namiki et al., 2006; Hare et al., 2006; Namiki et al., 2007a; Fahay, 2007. 


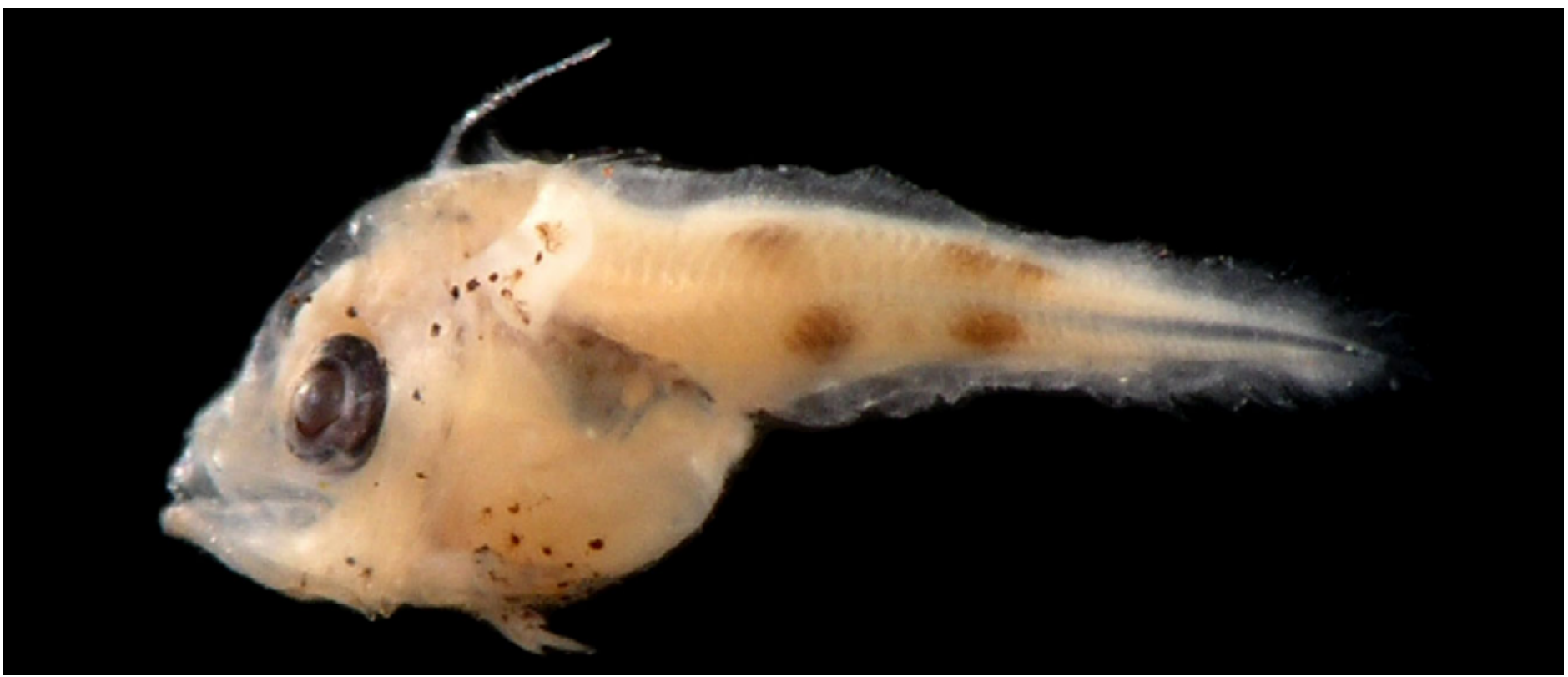

Figura 81: Bregmaceros nov sp. DZUFRJ 13487; Pré-flexão; CP 2,8 mm.

\section{Bregmaceros nov sp.}

Possui intestino curto e corpo alongado (52-59 miômeros) com menor número de pigmentos externos do que $B$. atlanticus. Nas larvas em pré-flexão (2,5-3,0 mm) os melanóforos da cabeça estão dispostos ao redor do raio occipital e apresentam três melanóforos sobre cada olho. Pigmentos no pedúnculo da nadadeira peitoral, sobre a massa visceral e no lado ventral do intestino. Possuem de dois a três melanóforos ventrais e dois dorsais opostos ao primeiro e terceiro pigmentos dorsais. A cabeça também apresenta menor número de melanóforos do que $B$. atlanticus. A primeira nadadeira dorsal é composta por um único raio prolongado localizado na região superior da cabeça, denominado raio occipital, que aparece no estágio de pré-flexão (antes da larva atingir 3,0 mm). Em exemplares maiores, o raio occipital alcança o meio da segunda nadadeira dorsal. A partir de 4,0 mm o corpo apresenta quatro melanóforos internos ventrais e quatro dorsais. Os pigmentos estão em menor número e distribuídos de maneira mais organizada que em $B$. atlanticus.

Tamanho: pré-flexão 2,8 mm.

Habitat: espécie marinha, epi-mesopelágica, ocorre em águas oceânicas. Anteriormente essa espécie era descrita como Bregmaceros mcclellandii Thompson,1840 que é endêmica do Oceano Índico.

\section{Georreferenciamento}

\begin{tabular}{|c|c|c|c|c|c|c|c|c|}
\hline DZUFRJ & Latitude (S) & Longitude (W) & Data & $\begin{array}{c}\text { Tipo de } \\
\text { arrasto }\end{array}$ & $\begin{array}{c}\text { Profundidade } \\
\text { de coleta }\end{array}$ & Rede & $\begin{array}{c}\text { Malha } \\
(\boldsymbol{\mu m})\end{array}$ & $\begin{array}{c}\mathbf{N}^{\circ} \text {. de } \\
\text { inds. }\end{array}$ \\
\hline 6226 & $22^{\circ} 34^{\prime} 05,0^{\prime \prime}$ & $040^{\circ} 19^{\prime} 40,0^{\prime \prime}$ & $17 / 05 / 2002$ & oblíquo & $600 \mathrm{~m}$ & cilíndrico-cônica & 500 & 1 \\
\hline
\end{tabular}

Referências: Houde, 1981; Houde, 1984; Matsuura et al., 1993; Harold \& Baltzegar, 2003; Namiki et al., 2006; Hare et al., 2006; Namiki et al., 2007a; Fahay, 2007. 


\section{Família Macrouridae}

A maioria das espécies da família Macrouridae é bentopelágica e vive em águas profundas. Ocorre desde o Ártico até a Antártica. Compreende quatro subfamílias e 27 gêneros com aproximadamente 350 espécies. Possuem o corpo alongado, cabeça grande e tronco curto terminando em uma cauda longa e com extremidade afilada. Não possuem nadadeira caudal. Podem apresentar uma nadadeira dorsal ou duas. No caso de duas nadadeiras dorsais, a primeira é curta e existe um espaço entre elas. As nadadeiras anal e dorsal são confluentes e a base da nadadeira anal é maior que da segunda nadadeira dorsal.

No Brasil já foram identificadas 30 espécies nas fases de larva e adulto. Nesse estudo é contemplada a espécie Coryphaenoides armatus. 


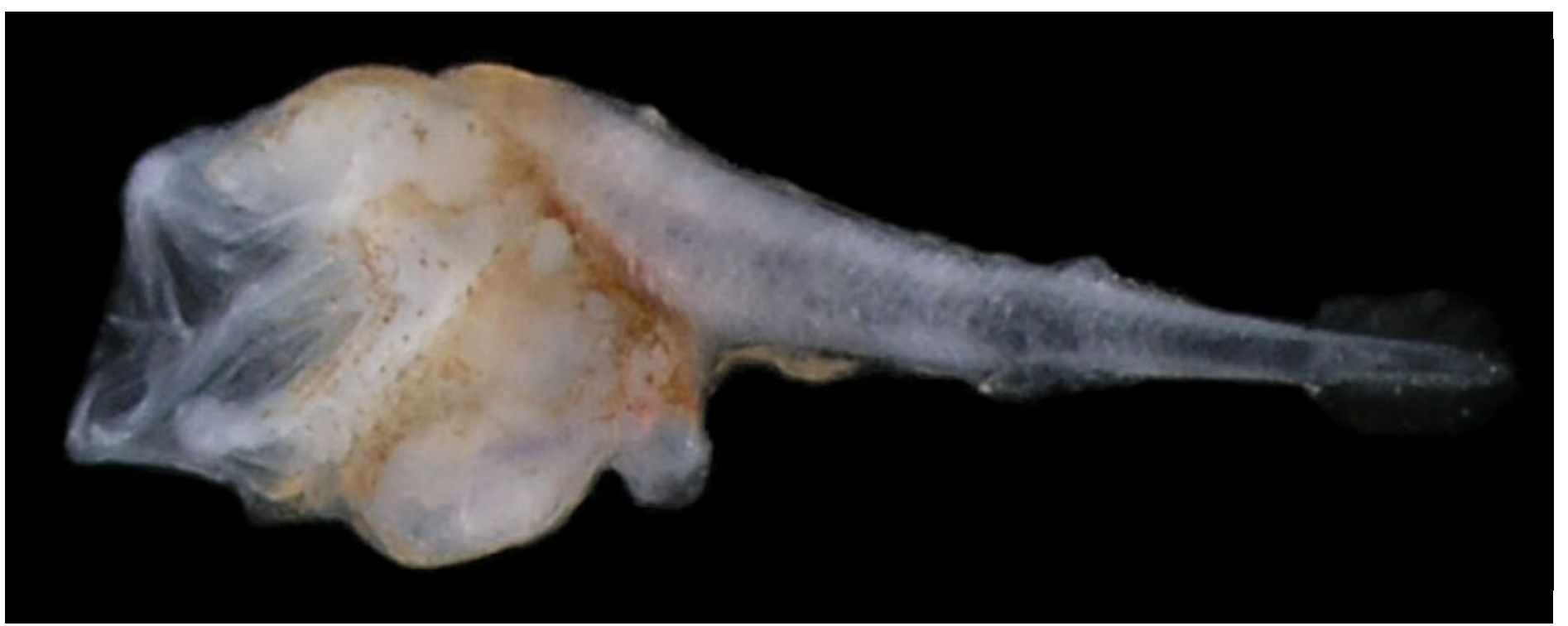

Figura 82: Coryphaenoides armatus. DZUFRJ 7514; CP 5,7 mm.

\section{Coryphaenoides armatus (Hector, 1875)}

Possui o corpo alto na região anterior terminando em uma cauda longa e fina. As bases das nadadeiras pélvica e peitoral são muito pedunculadas. Os raios da nadadeira anal são maiores que os da nadadeira dorsal. Possui um grande espaço entre as nadadeiras dorsais. A pigmentação se concentra na parte posterior da cabeça, na região peritoneal e na porção anterior do corpo. A cauda não possui pigmentação.

Tamanho: 5,7-18,0 mm.

Habitat: espécie marinha, bentopelágica, ocorre em águas tropicais e subpolares em profundidades entre 2.000 e $5.500 \mathrm{~m}$.

\section{Georreferencimento}

\begin{tabular}{|c|c|c|c|c|c|c|c|c|}
\hline DZUFR & Latitude (S) & Longitude (W) & Data & $\begin{array}{c}\text { Tipo de } \\
\text { arrasto }\end{array}$ & $\begin{array}{c}\text { Profundidade } \\
\text { de coleta }\end{array}$ & Rede & $\begin{array}{c}\text { Malha } \\
\text { ( } \boldsymbol{\mu m} \text { ) }\end{array}$ & $\begin{array}{c}\mathbf{N}^{\circ} \text {. de } \\
\text { inds. }\end{array}$ \\
\hline 7513 & $21^{\circ} 58^{\prime} 31,0^{\prime \prime}$ & $039^{\circ} 50^{\prime} 29,7^{\prime \prime}$ & $10 / 10 / 2001$ & oblíquo & $1.000 \mathrm{~m}$ & cilíndrico-cônica & 500 & 1 \\
\hline 7514 & $21^{\circ} 58^{\prime} 31,0^{\prime \prime}$ & $039^{\circ} 50^{\prime} 29,7^{\prime \prime}$ & $11 / 10 / 2001$ & oblíquo & $1.000 \mathrm{~m}$ & cilíndrico-cônica & 500 & 1 \\
\hline
\end{tabular}

Referências: Merrett, 2006; Fahay, 2007. 


\section{Família Phycidae}

A família Phycidae é marinha e ocorre no Atlântico, na África do Sul, Nova Zelândia e Japão. Compreende cinco gêneros com 25 espécies. Possuem cabeça e focinho arredondados. $O$ intestino é curto alcançando menos da metade do corpo. Presença de duas nadadeiras dorsais sem espinhos. A nadadeira pélvica tem três raios alongados.

No Brasil já foram identificadas três espécies nas fases de larva e adulto: Urophycis brasiliensis (Kaup, 1858); Urophycis cirrata (Goode \& Bean, 1896) e Urophycis mystacea Miranda Ribeiro, 1903. Nesse estudo é contemplada a espécie Urophycis cirrata. 


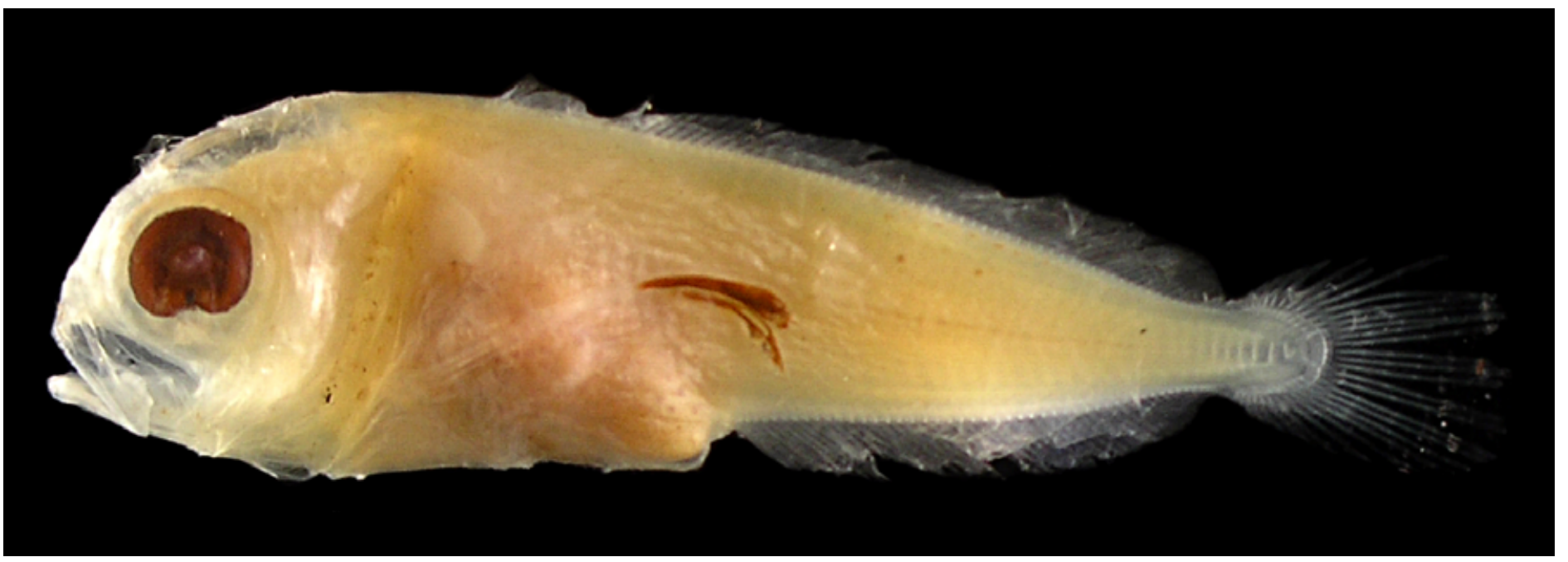

Figura 83: Urophycis cirrata. DZUFRJ 25290; Flexão; CP 10,5 mm.

\section{Urophycis cirrata (Goode \& Bean, 1896)}

Possui a cabeça e o focinho arredondados. A base da nadadeira peitoral é um pouco pedunculada. A nadadeira pélvica tem três raios longos com as extremidades pigmentadas. A distância pré-anal é curta representando menos da metade do corpo.

Tamanho: flexão 10,5 mm.

Habitat: espécie marinha, batidemersal, ocorre em águas tropicais em profundidades entre 360 e $470 \mathrm{~m}$.

Nome vulgar: Abrótea.

\section{Georreferencimento}

\begin{tabular}{|c|c|c|c|c|c|c|c|c|}
\hline DZUFRJ & Latitude (S) & Longitude (W) & Data & $\begin{array}{c}\text { Tipo de } \\
\text { arrasto }\end{array}$ & $\begin{array}{c}\text { Profundidade } \\
\text { de coleta }\end{array}$ & Rede & $\begin{array}{c}\text { Malha } \\
(\boldsymbol{\mu m})\end{array}$ & $\mathbf{N}^{\circ}$. de inds. \\
\hline 25290 & $22^{\circ} 28,5^{\prime}$ & $039^{\circ} 55,47^{\prime}$ & $16 / 06 / 2003$ & horizontal & superfície & nêuston & 500 & 1 \\
\hline
\end{tabular}

Referências: Comyns \& Bond, 2006; Fahay, 2007. 